\title{
Frequency and Env determinants of HIV-1 subtype $C$ strains from antiretroviral therapy-naive subjects that display incomplete inhibition by maraviroc
}

\author{
Katharina Borm ${ }^{1,2}$, Martin R. Jakobsen ${ }^{3}$, Kieran Cashin ${ }^{4}$, Jacqueline K. Flynn 1,4,5, Paula Ellenberg 1,4,
} Lars Ostergaard ${ }^{3}$, Benhur Lee ${ }^{6}$, Melissa J. Churchill ${ }^{1,7,8}$, Michael Roche ${ }^{1,9^{*}}$ and Paul R. Gorry ${ }^{1,4^{*}}$

\begin{abstract}
Background: Entry of human immunodeficiency virus type 1 (HIV-1) into cells involves the interaction of the viral gp120 envelope glycoproteins (Env) with cellular CD4 and a secondary coreceptor, which is typically one of the chemokine receptors CCR5 or CXCR4. CCR5-using (R5) HIV-1 strains that display reduced sensitivity to CCR5 antagonists can use antagonist-bound CCR5 for entry. In this study, we investigated whether naturally occurring gp120 alterations in HIV-1 subtype C (C-HIV) variants exist in antiretroviral therapy (ART)-naive subjects that may influence their sensitivity to the CCR5 antagonist maraviroc (MVC).

Results: Using a longitudinal panel of 244 R5 Envs cloned from 20 ART-naïve subjects with progressive C-HIV infection, we show that $40 \%$ of subjects $(n=8)$ harbored viruses that displayed incomplete inhibition by MVC, as shown by plateau's of reduced maximal percent inhibitions (MPIs). Specifically, when pseudotyped onto luciferase reporter viruses, 16 Envs exhibited MPIs below 98\% in NP2-CCR5 cells (range 79.7-97.3\%), which were lower still in 293-Affinofile cells that were engineered to express high levels of CCR5 (range 15.8-72.5\%). We further show that Envs exhibiting reduced MPIs to MVC utilized MVC-bound CCR5 less efficiently than MVC-free CCR5, which is consistent with the mechanism of resistance to CCR5 antagonists that can occur in patients failing therapy. Mutagenesis studies identified strain-specific mutations in the gp120 V3 loop that contributed to reduced MPIs to MVC.
\end{abstract}

Conclusions: The results of our study suggest that some ART-naive subjects with C-HIV infection harbor HIV-1 with reduced MPIs to MVC, and demonstrate that the gp120 V3 loop region contributes to this phenotype.

Keywords: HIV-1, Subtype C, Env, gp120, CCR5, Maraviroc

\section{Background}

Entry of human immunodeficiency virus type 1 (HIV1) into cells is mediated by the envelope glycoprotein complex (Env). Env exists as a trimer of heterodimers of

*Correspondence: michael.roche@unimelb.edu.au; paul.gorry@rmit.edu. au

${ }^{4}$ School of Health and Biomedical Sciences, College of Science, Engineering and Health, RMIT University, Melbourne, VIC 3001, Australia ${ }^{9}$ The Peter Doherty Institute for Infection and Immunity, University of Melbourne and Royal Melbourne Hospital, Melbourne, VIC 3000, Australia

Full list of author information is available at the end of the article gp120 surface and gp41 transmembrane glycoproteins that decorate the exterior of the virus particle (reviewed in [1]). Entry is initiated by the interaction between gp120 and cell surface CD4 [2-4], followed by a secondary interaction with a chemokine coreceptor, either CCR5 or CXCR4 [5-9]. HIV-1 Envs are classified as CCR5-using (R5) or CXCR4-using (X4) depending on the choice of coreceptor used for entry. HIV-1 Envs that can interact with either CCR5 or CXCR4 to enter cells are referred to as dual-tropic (R5X4).

The interaction between gp120 and CD4 leads to conformational changes in gp120 affecting the first, second 
and third variable loops (V1, V2, V3) and formation of the gp120 bridging sheet, which together comprise the coreceptor binding site (CoRbs) [10-12]. CCR5 is a G-protein coupled receptor that contains an $\mathrm{N}$-terminal domain and 7 transmembrane helices, the latter of which forms a hydrophobic cavity at the cell membrane $[13,14]$. The stem of the gp120 V3 loop and the bridging sheet of CD4-bound gp120 interact with the $\mathrm{N}$-terminal domain of CCR5, and the tip of the V3 loop interacts with the second extracellular loop (ECL2) of the coreceptor [1517]. After coreceptor binding, further conformational rearrangements in gp41 occur that lead to virus-cell fusion and release of the viral core into the cell.

Maraviroc (MVC) is a CCR5 antagonist that is approved for use as an antiretroviral drug in treatment-experienced and -naïve HIV-1 infected subjects shown to harbour only R5 viruses [18-20]. Furthermore, since R5 HIV-1 strains are preferentially transmitted from person to person, MVC has potential for use in pre-exposure prophylaxis (PrEP) and microbicide formulations to prevent new infections [21-23]. Other experimental CCR5 antagonists that are not used clinically include vicriviroc (VVC) and aplaviroc (APL). MVC and other CCR5 antagonists inhibit HIV-1 entry by binding within the hydrophobic pocket of CCR5 [24-26], thereby altering the conformation of the CCR5 extracellular loops [27] such that they are no longer recognized by gp120. Consequently, MVC and other CCR5 antagonists are allosteric inhibitors of HIV-1 entry rather that competitive inhibitors.

Some HIV-1 infected subjects experience resistance to MVC after treatment with MVC-containing ART regimens $[18,19]$. There are two principal mechanisms that contribute to the emergence of MVC-resistant HIV-1 strains in these subjects; (1) a selection for minor X4 or R5X4 HIV-1 strains that are not inhibited by CCR5 antagonists [19] or (2) acquisition of the ability of R5 viruses to interact with the MVC-bound conformation of CCR5 [28-30]. In the latter scenario that typifies "genuine" MVC resistance, the use of MVC-bound CCR5 by resistant viruses is characterized not by increases in the $50 \%$ inhibitory concentrations $\left(\mathrm{IC}_{50}\right)$ of $\mathrm{MVC}$, but rather by reductions in the maximal percent inhibition (MPI) in viral infection assays, with plateaus of incomplete inhibition being evident despite saturating drug concentrations [28-30]. Considering the extensive variability of Env sequence between HIV-1 strains, and the inherently flexible nature of coreceptor engagement by Env, we hypothesized that the existence of clinical HIV-1 strains isolated from ART-naïve subjects that exhibited reduced MPIs to MVC was likely [31, 32]. In fact, recent studies have shown that Envs cloned from viruses isolated from treatment-naïve individuals chronically infected with HIV-1 subtype $\mathrm{C}$ (C-HIV), may be more efficient at interacting with MVC bound CCR5 than Envs from viruses isolated from subjects with acute infection [33, 34]. However, usage of MVC-bound CCR5 by viruses characterized in these studies was generally very inefficient compared to that which occurs in genuinely resistant HIV-1 strains isolated from patients failing MVC therapy. Whether such baseline usage of MVC-bound CCR5 develops further at late stages of infection and occurs at potentially clinically relevant efficiencies is yet to be determined.

Globally C-HIV is the most rapidly spreading HIV-1 subtype, yet paradoxically, it is less virulent than other subtypes ex vivo [35, 36], suggesting unique molecular mechanisms that simultaneously impair fitness and facilitate favourable transmission events. A number of these unique features appear to involve the Env glycoproteins and entry mechanisms. For example, in contrast to HIV-1 subtype B infection where, if untreated, progression to advanced stages of infection is frequently accompanied by a switch in coreceptor usage from R5 to R5X4 or X4 variants (reviewed in [37]), in C-HIV infection the detection of $\mathrm{R} 5 \mathrm{X} 4$ and $\mathrm{X} 4$ variants is relatively rare, even at late stages of infection ([38] and references within). Furthermore, R5 C-HIV strains have been shown to exhibit alterations in their efficiency of CCR5 and CD4 usage [39], and usage of particular alternative coreceptors in vitro [40-42]. Together, these features of may influence how C-HIV strains respond to inhibition by CCR5 antagonists such as MVC.

In this study we investigated the frequency, efficiency and underlying Env determinants of HIV-1 strains with reduced MPIs to MVC within an ART-naïve, longitudinal cohort of 20 subjects who progressed from chronic to late stages of C-HIV infection over a 3 year period [38]. By functionally characterizing 244 independent Envs derived from plasma of these subjects, we demonstrate that 8 subjects (40\%) harbored HIV-1 strains that could interact with MVC-bound CCR5 resulting in reduced MPIs to MVC. We further show that these variants have strain-specific mutations in the gp120 V3 loop region that contribute to this phenotype. However, strains with reduced MPIs to MVC did not emerge more frequently at advanced infection compared to chronic infection, suggesting that they are not selected for during disease progression. Together, our findings suggest that some ART-naïve subjects infected with C-HIV harbor viruses that display altered sensitivity to MVC, which involves strain-specific amino acid alterations the gp120 V3 loop region of Env.

\section{Methods}

\section{Ethics statement}

Written informed consent was provided by the subjects for the use of stored plasma samples (from which the Env 
clones were derived), as stated previously [38]. Ethics approval for the use of these samples was granted by the Medical Research Council of Zimbabwe (MRCZ/A/918) and by the Central Medical Scientific Ethics Committee of Denmark (624-01-0031).

\section{Cells}

293T cells, and NP2-CD4/CCR5 cells [43] were maintained in Dulbecco's Modified Eagles Medium (DMEM) supplemented with $10 \%$ (vol/vol) fetal calf serum (FCS) and $100 \mu \mathrm{g} / \mathrm{ml}$ of penicillin and streptomycin. CD4 selection in NP2 cells was maintained by $500 \mu \mathrm{g} / \mathrm{ml}$ of G418 and CCR5 expression was maintained by $1 \mu \mathrm{g} / \mathrm{ml}$ of puromycin. 293-Affinofile cells [44] were maintained in DMEM supplemented with $10 \%$ ( vol/vol) FCS, $100 \mu \mathrm{g} /$ $\mathrm{ml}$ of penicillin and streptomycin, $50 \mu \mathrm{g} / \mathrm{ml}$ of blasticidin and $200 \mu \mathrm{g} / \mathrm{ml}$ of G418.

\section{Env clones}

The sequences of the C-HIV Env clones used here have been reported previously [38], and their GenBank accession numbers are shown in Additional file 1: Table S1.

\section{Production and titration of Env-pseudotyped luciferase reporter viruses}

Env-pseudotyped luciferase reporter viruses were produced by transfection of 293T cells with pCMV $\Delta$ P1 $1 \Delta$ envpA, pHIV-1Luc, and pSVIII-Env plasmids using lipofectamine 2000 (Invitrogen) at a ratio of $1: 3: 1$, as described previously $[45,46]$. Supernatants were harvested $48 \mathrm{~h}$ later, filtered through $0.45 \mu \mathrm{M}$-pore size filters, and stored at $-80{ }^{\circ} \mathrm{C}$. The infectivity of virus stocks was determined by titration in NP2-CD4/CCR5 cells. For subsequent infection experiments of all cell lines, viral input was normalized to $2 \times 10^{5}$ relative light unit (RLU) counts.

\section{HIV-1 inhibition assays}

The sensitivity of Env-pseudotyped luciferase reporter viruses to inhibition by MVC was determined as described previously [29, 47, 48]. Briefly, to obtain 293-Affinofile cells with a medium/high level of CD4 and high level of CCR5 (termed CD $4^{\text {med }} / C C R 5^{\text {hi }}$ cells), 293-Affinofile cells were induced for $20 \mathrm{~h}$ prior to seeding with $2.5 \mathrm{ng} / \mathrm{ml}$ of minocycline (for CD4 expression) and $2.0 \mu \mathrm{M}$ of Ponasterone A (for CCR5 expression). In our hands this produces a cell type that expresses approximately 180,000 molecules per cell of CD4 and approximately 95,000 molecules per cell of CCR5, as determined by quantitative flow cytometry (qFACS) as described previously [49]. NP2-CD4/CCR5 cells and 293-Affinofile $\mathrm{CD} 4^{\text {med }} / \mathrm{CCR} 5^{\text {hi }}$ cells $\left(1 \times 10^{4}\right.$ in $\left.100 \mu \mathrm{l}\right)$ were seeded in flat-bottom 96-well plates. $24 \mathrm{~h}$ later the media was removed from cells and replaced with $100 \mu \mathrm{l}$ of fresh media with fivefold dilutions of MVC (at a $\times 2$ concentration) for $30 \mathrm{~min}$ at $37{ }^{\circ} \mathrm{C}$. The concentration range for MVC was $5 \mu \mathrm{M}$ to $0.064 \mathrm{nM}$. NP2-CD4/CCR5 cells and 293-Affinofile CD $4^{\text {med }} / C C R 5{ }^{\text {hi }}$ cells were inoculated with Env-pseudotyped luciferase reporter viruses in $100 \mu \mathrm{l}$ for $12 \mathrm{~h}$ at $37^{\circ} \mathrm{C}$. Following this, the inoculum was removed and replaced with fresh media. The inhibitor concentrations were maintained throughout the subsequent culture period. Infected cells were incubated at $37{ }^{\circ} \mathrm{C}$ for a total of $72 \mathrm{~h}$. The level of HIV-1 entry was measured by luciferase activity in cell lysates (Promega) according to the manufacturers protocol. Luminescence was measured using a FLUOStar microplate reader (BMG). Background activity was assessed by mock-infected cells and was subtracted from all wells. The amount of luciferase activity in cells treated with MVC was expressed as a percentage of that in untreated cells. The percentage of inhibition was calculated by subtracting this number from 100 . The data were fitted with a nonlinear function, and alterations in inhibitor sensitivity were assessed by reductions in the MPI as described previously [47].

\section{Measurement of CD4/CCR5 usage efficiency}

293-Affinofile cells were infected with Env-pseudotyped luciferase reporter viruses as described previously [29, 49]. Briefly, 48 populations of cells expressing different combinations of CD4 and CCR5 levels were generated by inducing cells with twofold serial dilutions of minocycline $(0.156-5.0 \mathrm{ng} / \mathrm{ml})$ and ponasterone A $(0.0156-2.0 \mu \mathrm{M})$. $\mathrm{CD} 4$ and CCR 5 concentrations were determined by quantitative flow cytometry (qFACS) as described previously $[44,50]$. CD4 expression ranged from 1600 to 190,000 molecules per cell; CCR5 expression ranged from 1500 to 95,000 molecules per cell. The induced cell populations were then either left untreated or treated with $10 \mu \mathrm{M}$ $\mathrm{MVC}$ for $30 \mathrm{~min}$ at $37^{\circ} \mathrm{C}$, after which they were inoculated with $2 \times 10^{5} \mathrm{RLU}$ of Env-pseudotyped luciferase reporter viruses and were analyzed for levels of HIV-1 entry $72 \mathrm{~h}$ later as described above. In experiments using MVCtreated cells, the MVC concentration was maintained throughout the culture period. The relative level of virus entry achieved by each Env was expressed as a percentage of that achieved in 293-Affinofile cells expressing the highest concentrations of CD4 and CCR5. For infections performed in the presence of MVC, virus entry was expressed as a percentage of that achieved in untreated wells.

\section{Env mutagenesis}

Env mutants were generated with a Quick Change II sitedirected mutagenesis kits (Agilent Technologies) according to the manufacturers' protocol, and were verified by full-length sequencing. 


\section{Results and discussion}

Detection of incomplete inhibition by MVC in HIV-1 strains from a treatment-naïve, longitudinal cohort of subjects with progressive HIV-1 subtype $C$ infection

Recent cross sectional studies demonstrated levels of incomplete inhibition of C-HIV strains by MVC that differed between transmitted and chronic Envs [33, 34]. However, the levels of incomplete inhibition were generally relatively low, with the majority of Envs tested exhibiting residual entry levels of just $0.01-1.0 \%$ in NP2-CD4/ CCR5 cells in the presence of a saturating concentration of MVC [34]. Since the threshold for the laboratory diagnosis of clinical MVC-resistance in similar cell lines (U87-CD4/CCR5) is typically at 5\% residual entry or above in the presence of MVC [51], whether levels of residual entry below $5 \%$ are clinically relevant remains to be determined.

To better understand the frequency and magnitude of residual entry by $\mathrm{C}$-HIV strains in the presence of MVC that may arise in untreated subjects during progressive infection, we first screened the infectivity of 244 R5 C-HIV Envs that were isolated from longitudinal plasma samples of 20 ART-naïve subjects from rural Zimbabwe. These subjects progressed from chronic to advanced stages of infection over a 3 year period [38]. Figure 1 shows the percentage of residual entry of Envpseudotyped luciferase reporter viruses when inoculated onto NP2-CD4/CCR5 cells in the presence of saturating MVC $(5 \mu \mathrm{M})$. For these and subsequent results, "E" refers to Envs cloned from plasma taken at study enrolment, "I" refers to Envs cloned at an intermediate sampling timepoint 1 year after study enrolment, and "F" refers to Envs cloned at the final timepoint 3 years after study enrolment [38]. Controls included (1) luciferase viruses pseudotyped with the R5 Envs ADA, YU2 or JRCSF, which as expected, exhibited levels of residual entry $<0.04 \%$ indicative of MVC sensitivity; (2) virus pseudotyped with a MVC-resistant Env that was generated in vitro (MVCRes) [48] which, consistent with the results of previous studies [47] exhibited levels of residual entry between 30 and 40\%; and (3) virus pseudotyped with the parental Env to which MVC-Res was derived (MVC-Sens), which we have previously shown has a degree of inherent baseline ability to interact with MVC-bound CCR5 [47], and consistent with those studies exhibited levels of residual entry $\sim 2 \%$. From the results of our control infections, and in consideration of thresholds applied for MVC-Sens Env, we applied a cutoff of $>2 \%$ residual entry in these analyses for the identification of C-HIV Env clones that may exhibit residual entry levels that could potentially be clinically relevant.

Analysis of viruses pseudotyped with the C-HIV Envs showed that $8 / 20$ subjects (40\%) had Env variants that displayed residual entry levels $>2 \%$ in the presence of saturating MVC (Fig. 1). Residual entry levels ranged from 2.7 to $20.3 \%$ (Table 1 ). Overall, there was no temporal pattern for emergence of Envs displaying residual entry in the presence of MVC, with these Envs detectable within early, intermediate and final plasma samples. However, the number of Env clones tested at each of the timepoints was relatively small, so further studies of greater numbers of Env clones may be required to observe a relationship between Envs displaying a residual entry phenotype and disease stage.

Together, our results show that a proportion of C-HIV Envs from our cohort is capable of mediating entry into NP2-CD4/CCR5 cells in the presence of MVC. Our results confirm the observations of others who have found a portion of acute disease-derived and chronic disease-derived Envs with similar phenotypes [33, 34]. Indeed both Parker et al. and Ping et al. found the residual entry in the presence of saturating MVC to be more frequent in chronic disease-derived Envs. We have extended these observations by showing that this phenomenon does not appear to increase during the course of active disease as we found no difference in the proportion of the residual entry phenotype between the enrolment, intermediate and final timepoints. Interestingly, we have found that, at a population level, the ability of our panel of C-HIV Envs to utilise the alternative coreceptors CCR3 and FPRL1 increased as disease advanced suggestive of alterations in the flexibility of Env to engage coreceptor [40]; the individual alternative coreceptor usage characteristics of the Envs that display entry in the presence of $\mathrm{MVC}$, in comparison to a representative Env from each subject that is completely inhibited by MVC, is shown in Additional file 2: Table S2. Increased flexibility in coreceptor engagement has been observed previously in studies of disease progression in subtype B infection $[52,53]$, and this has been associated with reduced sensitivity to RANTES and TAK-779 as determined by increases in $\mathrm{IC}_{50}$ values $[53,54]$. Recent evidence suggests that this is also the case for MVC [55]. Interestingly, MVC resistance is commonly associated with increased Env dependence on interactions with the CCR $5 \mathrm{~N}$-terminus, likely signalling a movement toward regions of CCR 5 not modified by MVC binding [29, 30, 48]. Conversely, reduced sensitivity to $\mathrm{MVC}$, as determined by increases in $\mathrm{IC}_{50} / \mathrm{IC}_{90}$, is associated with reduced dependence on the CCR5 N-terminus $[31,55]$. Taken together, our results suggest that increased flexibility of CCR5 usage may not necessarily lead to strains with reduced MPIs to MVC.

Whilst our data demonstrates the presence of C-HIV Envs with baseline reductions in MPI to MVC, there is evidence that this phenotype is not unique to C-HIV. Parker et al. observed similar levels of reduced baseline 
Berm et al. Retrovirology (2016) 13:74

Page 5 of 13
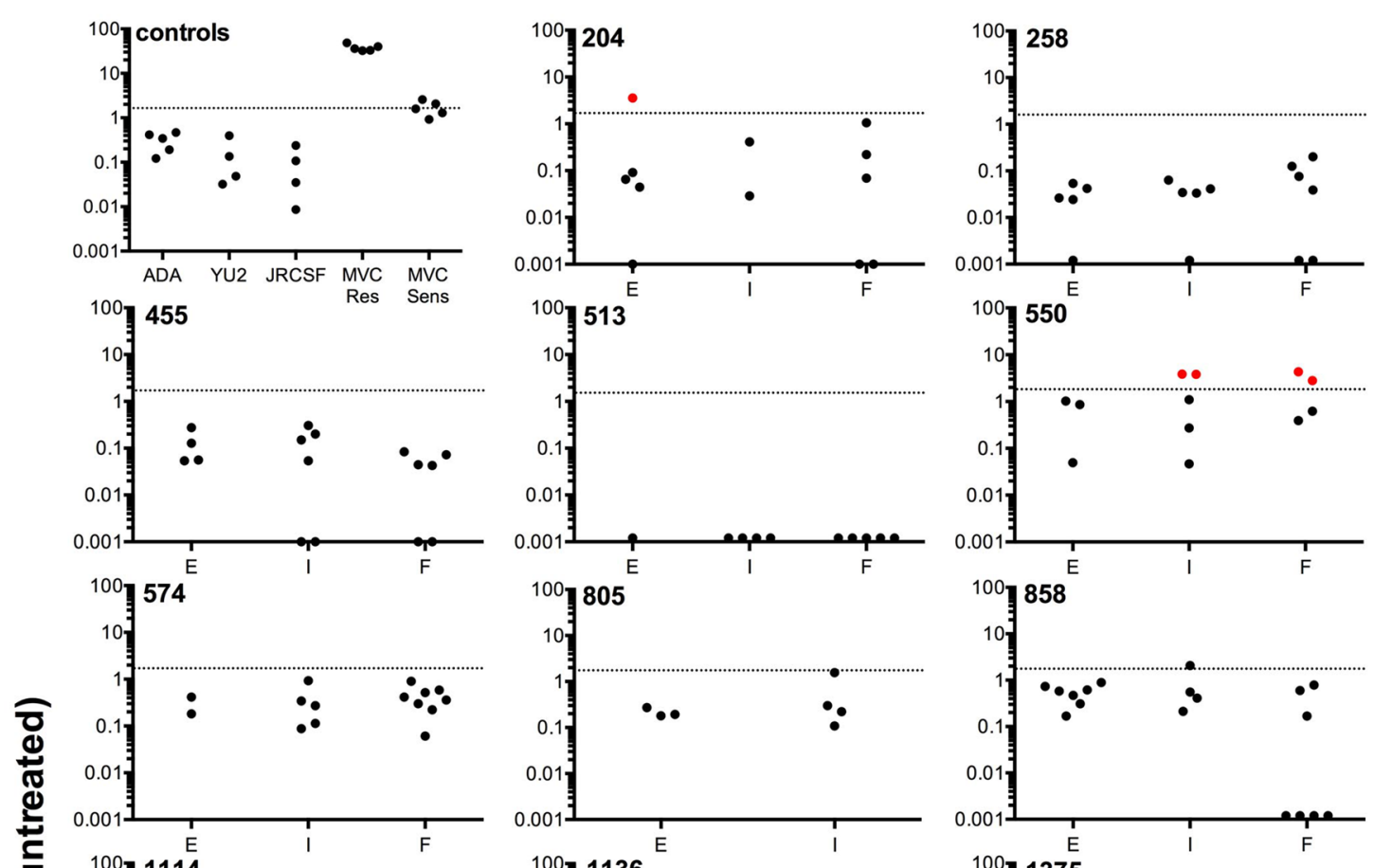

일
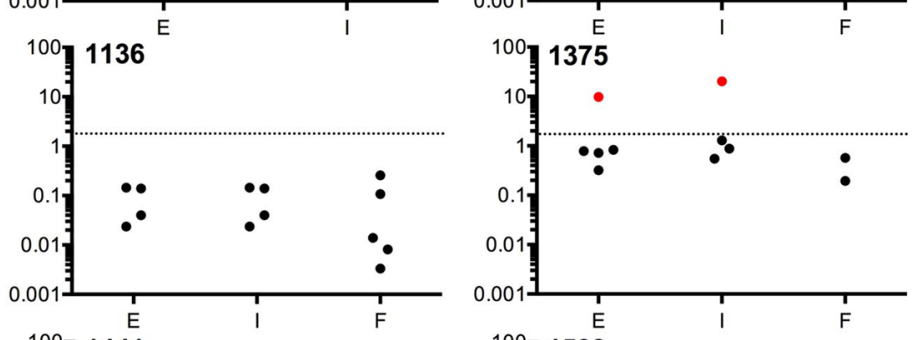

岁
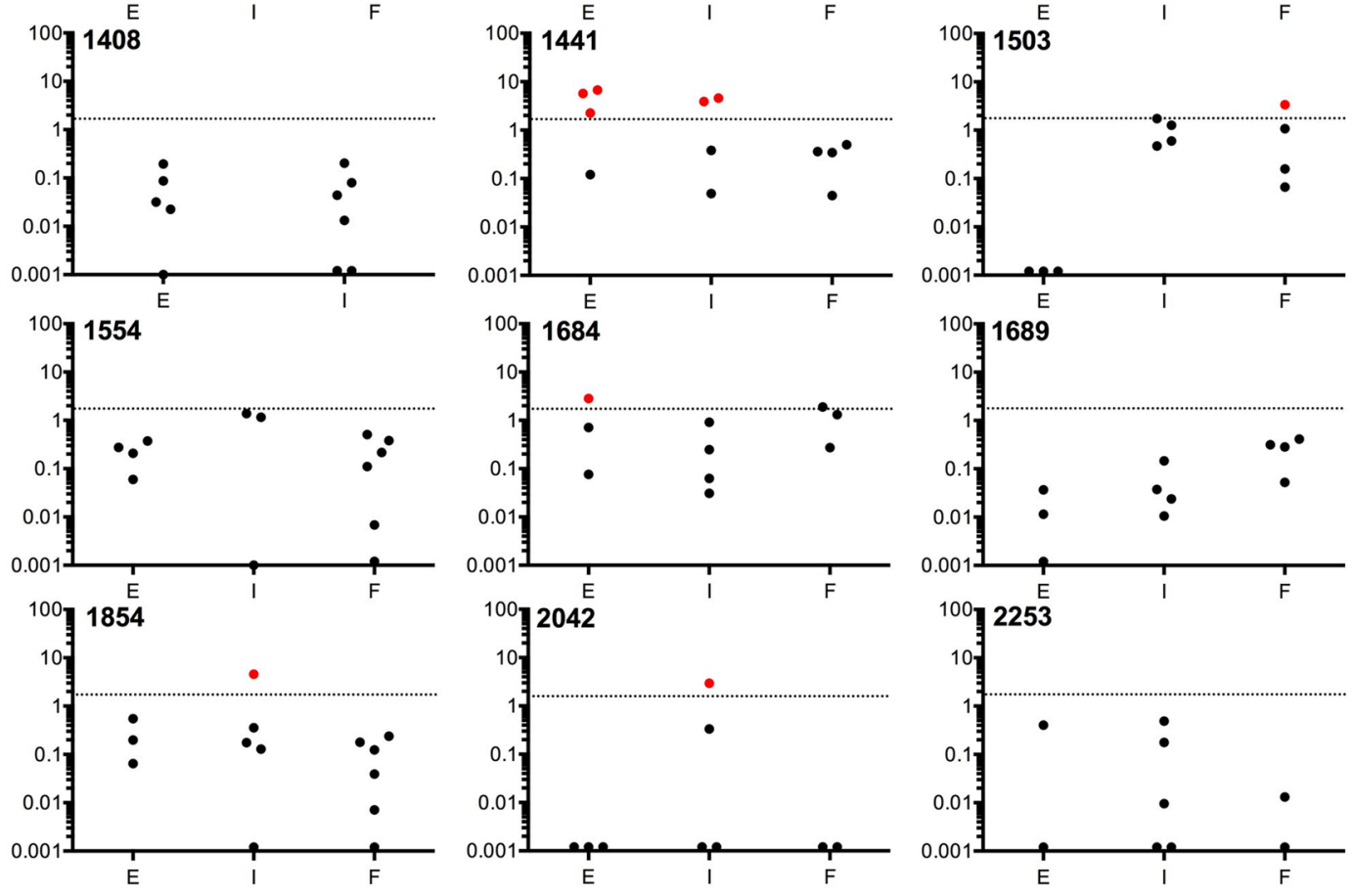

Fig. 1 Residual viral entry in the presence of saturating MVC in NP2-CD4/CCR5 cells infected with HIV-1 subtype C Envy from a longitudinal progressor study. Luciferase reporter viruses pseudotyped with HIV-1 subtype C Envs were used to infect NP2-CD4/CCR5 cells in the presence of saturating amounts of MVC. Residual entry was expressed as the percentage of entry achieved compared to no drug controls. The data points are means of triplicate wells. Dotted line, arbitrary cutoff value set by MVC-Sens residual entry; red dots, clones above cutoff and thus considered resistant; black dots, clones below cutoff and thus considered sensitive. E enrolment timepoint, I intermediate timepoint, F final timepoint 
Table 1 Residual entry of selected HIV-1 subtype C Envs in the presence of MVC in NP2-CD4/CCR5 and 293-Affinofile $\mathrm{CD} 4^{\text {med }} /$ CCR $^{\text {hi }}$ cells

\begin{tabular}{|c|c|c|c|}
\hline Patient ID & Env clone & $\begin{array}{l}\text { Residual entry } \\
\text { in NP2 cells }(\%)^{\mathrm{a}}\end{array}$ & $\begin{array}{l}\text { Residual entry } \\
\text { in Affinofile cells (\%) }\end{array}$ \\
\hline & ADA & $0.25 \pm 0.04$ & n.a. \\
\hline & YU2 & $0.04 \pm 0.02$ & $0.26 \pm 0.02$ \\
\hline & JRCSF & $0.09 \pm 0.02$ & $0.18 \pm 0.02$ \\
\hline & MVCres & $37.8 \pm 1.01$ & $68.45 \pm 14.35$ \\
\hline & MVCsens & $1.82 \pm 0.2$ & $47.28 \pm 2.23$ \\
\hline 204 & $E-7$ & $3.6 \pm 0.09$ & $36.24 \pm 5.01$ \\
\hline \multirow[t]{4}{*}{550} & $1-2$ & $3.80 \pm 0.71$ & $52.6 \pm 13.87$ \\
\hline & $1-7$ & $3.84 \pm 1.00$ & $36.2 \pm 1.81$ \\
\hline & $F-12$ & $4.32 \pm 1.32$ & $60.32 \pm 7.20$ \\
\hline & $\mathrm{F}-20$ & $2.80 \pm 1.11$ & $38.83 \pm 4.09$ \\
\hline \multirow[t]{2}{*}{1375} & $\mathrm{E}-2$ & $9.73 \pm 2.50$ & $84.20 \pm 8.99$ \\
\hline & $1-8$ & $20.34 \pm 5.23$ & $69.03 \pm 9.10$ \\
\hline \multirow[t]{5}{*}{1441} & $E-1$ & $5.70 \pm 0.47$ & $44.77 \pm 2.55$ \\
\hline & $E-2$ & $2.7 \pm 1.00$ & $53.69 \pm 9.14$ \\
\hline & $E-6$ & $6.72 \pm 0.66$ & $67.26 \pm 9.58$ \\
\hline & $1-2$ & $3.90 \pm 0.49$ & $68.34 \pm 11.52$ \\
\hline & $1-9$ & $4.57 \pm 0.42$ & $79.78 \pm 4.18$ \\
\hline 1503 & $\mathrm{~F}-7$ & $3.37 \pm 0.71$ & n.a. \\
\hline 1684 & $E-7$ & $2.84 \pm 1.74$ & $27.46 \pm 3.51$ \\
\hline 1854 & $1-7$ & $4.56 \pm 0.73$ & n.a. \\
\hline 2042 & $1-38$ & $2.95 \pm 0.86$ & $38.77 \pm 0.53$ \\
\hline
\end{tabular}

n.a. not done

${ }^{a}$ Mean $\%$ residual entry \pm standard deviation from two independent experiments

MPI in chronic-derived Envs from both B- and C-HIV [56]. In addition, the MVC-Sens control Env for our assays that displays reduced baseline MPI, is derived from the CC1/85 isolate, itself a B-HIV strain [28]. Thus, the phenomenon of baseline MPI reductions to MVC is unlikely to be limited to C-HIV and may be a more general feature of chronic derived Envs.

\section{Levels of incomplete HIV-1 inhibition by MVC are more pronounced in 293-Affinofile CD4 ${ }^{\text {med }} /$ CCR $^{\text {hi }}$ cells}

We have previously demonstrated that obscure or borderline MVC resistance profiles seen in U87-CD4/CCR5 and NP2-CD4/CCR5 cells are amplified in 293-Affinofile cells [47]. This may be related to a higher level of CCR5 expression on 293-Affinofile cells engineered to express high levels of CCR5, or expression of conformations of CCR5 not bound by MVC [33, 47]. We therefore conducted HIV-1 entry experiments in 293-Affinofile cells that were induced to express moderate CD4 levels and high CCR5 levels (293-Affinofile CD $4^{\text {med }} / C C R 5^{\text {hi }}$ ), in the presence of saturating MVC $(10 \mu \mathrm{M})$. Table 1 compares the residual entry in the presence of MVC between experiments conducted in NP2-CD4/CCR5 cells and 293-Affinofile $C D 4^{\mathrm{med}} / \mathrm{CCR} 5^{\mathrm{hi}}$ cells. The residual entry levels in 293-Affinofile CD $4^{\text {med }} / C C R 5^{\text {hi }}$ cells by the Envs tested ranged from 27.5 to $84.2 \%$, which are values approximately 7 - to 20 -fold greater than those derived from the NP2-CD4/CCR5 cell experiments. Importantly, control experiments with viruses pseudotyped with YU2 and JRCSF Envs demonstrated residual entry levels $<0.5 \%$ in 293-Affinofile CD $4^{\text {med}} / C C R 5^{\text {hi }}$ cells, confirming that 293-Affinofile cells have greater sensitivity for detection of HIV-1 strains that are incompletely inhibited by MVC without compromising specificity.

Whilst the results of the preceding experiments demonstrate the frequency and magnitude of C-HIV Envs displaying a residual entry despite a saturating concentration of MVC, suggesting usage of MVC-bound CCR5 for entry, bone fide MVC resistance is characterized by plateaus of incomplete inhibition in response to escalating drug concentrations [28]. We therefore next performed confirmatory titration experiments on 14 of the incompletely inhibited C-HIV Envs from 6 subjects, in 293-Affinofile CD $4^{\text {med }} / C C R 5^{\text {hi }}$ cells, with comparison to a representative Env cloned from the same plasma sample that did not display residual entry in the presence of MVC (Fig. 2). As expected, most of the Envs that did not display residual entry in the presence of MVC achieved MPIs of $100 \%$; the exception to this was Env $550-\mathrm{I}-2$, which although completely inhibited by MVC in NP2CD4/CCR5 cells, displayed an MPI of $92.7 \%$ in 293-Affinofile CD $4^{\text {med }} /$ CCR $5^{\text {hi }}$ cells (Fig. 2; Table 2). These results suggest that Env 550-I-2 may also possess a low level of altered MVC sensitivity that was not detected in the NP2-CD4/CCR5 cell screen. All the Envs that displayed residual entry despite MVC in both NP2-CD4/CCR5 cells and 293-Affinofile CD $4^{\text {med}} / C C R 5^{\text {hi }}$ cells exhibited plateaus of incomplete inhibition in response to escalating MVC concentrations (Fig. 2), with MPIs ranging from 27.5 to $72.6 \%$. These MPIs are consistent with the definition of "moderate" to "low level" MVC resistance, respectively, that has been determined for viruses isolated from patients failing MVC-containing ART regimens [29].

Our results with 293 -Affinofile $\mathrm{CD} 4^{\text {med }} /$ CCR $5^{\text {hi }}$ cells demonstrate a striking phenotypic similarity between the Env clones with reduced MPIs to MVC that we have detected in treatment naïve individuals and Env clones isolated from individuals who have failed MVC therapy $[29,30]$. Based on the plateaus in MPI in 293-Affinofile $\mathrm{CD} 4^{\mathrm{med}} / \mathrm{CCR} 5^{\mathrm{hi}}$ cells, the Env clones with reduced MPIs to MVC characterized here are likely interacting with MVC-bound forms of CCR5 and with an efficiency similar to strains with genuine resistance to MVC [29]. Our 


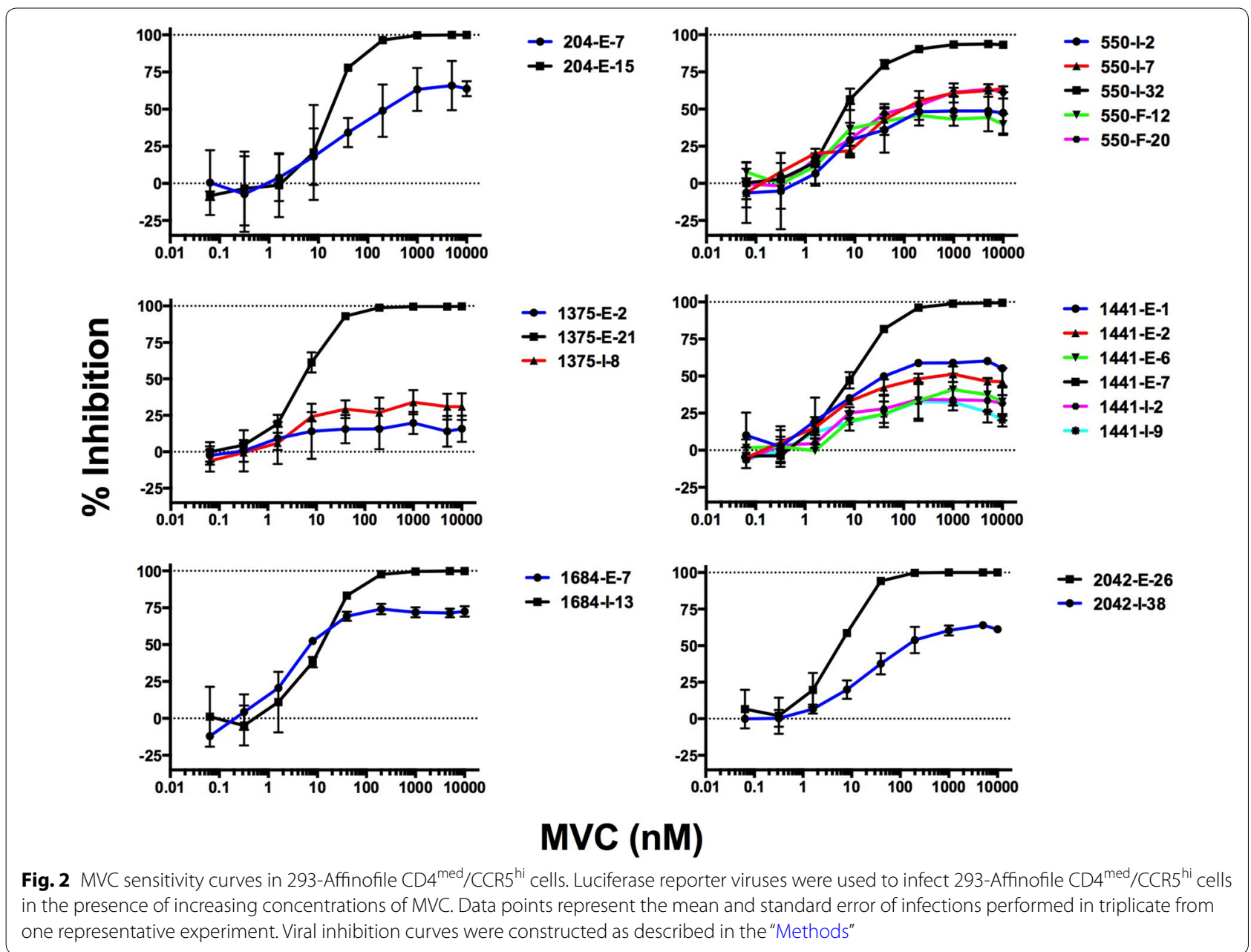

findings further highlight the efficiency of 293-Affinofile $\mathrm{CD} 4^{\text {med}} / \mathrm{CCR} 5^{\text {hi }}$ cells in determining the magnitude of reduced MPIs by strains with altered MVC sensitivity. This may be due to the high levels of CCR5 expression on these cells when maximally induced with Ponasterone, higher than seen on other cell types [34, 47]. At high concentrations of MVC, this would lead to a greater density of MVC bound CCR5 leading to a more efficient interaction between CCR5 and MVC resistant gp120. Conversely, 293-Affinofle cells may express a minority population of CCR5 that cannot be bound by MVC but can be bound by gp120 [33]. This minority species may only become relevant when CCR5 expression is induced to high levels on these cells. The concept of distinct forms of CCR5 expressed on different cell types has been proposed as a reason as to why CCR5 antagonist resistance manifests itself differently between primary CD4+ T cells and engineered cell lines such as TZM-bl [57]. Our results suggest that 293 -Affinofile $\mathrm{CD} 4^{\mathrm{med}} / \mathrm{CCR} 5^{\text {hi }}$ cells may provide greater sensitivity for the detection of HIV-1 strains that are incompletely inhibited by MVC.
The magnitude of reduced MPIs to MVC by C-HIV Envs is related to the efficiency of usage of MVC bound CCR5 Envs displaying moderate to low level MVC resistance have been shown to interact with the MVC-bound CCR5 complex relatively inefficiently compared to their interactions with drug-free CCR5 [47]. We therefore next used affinity profiling to quantify the ability of two C-HIV Envs, representing those with the highest (1684-E-7; MPI 72.6\%) and lowest MPIs (1375-E-2; MPI $16.5 \%$ ) in response to escalating concentrations of MVC (Table 2), to interact with MVC-bound CCR5. To do this we used the 293-Affinofile affinity profiling system where CD4 and CCR5 levels are controlled by separate inducible promoters, permitting independent variation of CD4 and CCR5 expression over a physiological concentration range [50]. When 48 differentially induced cell populations are subjected to entry assays with Env pseudotyped luciferase viruses, relative efficiencies of CD4- and CCR5-usage can be inferred. Results of the affinity profiling experiments are shown in Fig. 3, and illustrate that in the absence of MVC, the Envs that are 
Table 2 Maximal percent inhibition (MPI) of selected HIV-1 subtype C Envs by maraviroc in 293-Affinofile CD4 ${ }^{\text {med/ }}$ CCR5 ${ }^{\text {hi }}$ cells

\begin{tabular}{llcr}
\hline Patient ID & Env clone & MPI (\%) & SD (\%) \\
\hline 204 & E-15 & 100.13 & 1.66 \\
& E-7 & 68.65 & 16.62 \\
& I-32 & 92.7 & 0.62 \\
& I-2 & 49.03 & 13.75 \\
& I-7 & 65.38 & 3.33 \\
& F-12 & 43.39 & 1.42 \\
& F-20 & 62.65 & 2.09 \\
& E-21 & 100.01 & 0.69 \\
& E-2 & 16.54 & 10.53 \\
& I-8 & 30.87 & 9.17 \\
& E-7 & 99.25 & 0.56 \\
& E-1 & 60.47 & 3.94 \\
& E-2 & 48.02 & 5.56 \\
& E-6 & 36.85 & 12.35 \\
& I-2 & 32.92 & 12.34 \\
& I-9 & 27.51 & 0.05 \\
& I-13 & 100.27 & 1.46 \\
& E-7 & 72.63 & 2.91 \\
& E-26 & 100.99 & 1.57 \\
& I-38 & 63.55 & 1.30 \\
\hline
\end{tabular}

MPI maximal percent inhibition, SD standard deviation

${ }^{a}$ Mean and ${ }^{b}$ standard deviation of three independent experiments

completely- or incompletely inhibited by MVC from both subjects have similar infectivity profiles suggesting similar usage efficiencies for both CD4 and CCR5. However, in the presence of MVC both of the incompletely inhibited Envs required much higher levels of CCR5 to achieve detectable levels of entry. This was particularly the case for 1684-E-7 Env that displayed the highest MPI to MVC, which supports the conclusion that the magnitude of the reduced MPI to MVC is determined by the efficiency of the interaction with MVC-bound CCR5.

\section{Amino acid determinants of HIV-1 strains with reduced MPIs to MVC map to the V3 gp120 region and are subject-specific in the C-HIV cohort}

As previous studies of B-HIV Envs have shown, changes in the gp120 V3 loop contribute to the emergence of resistance to CCR5-antagonist HIV-1 entry inhibitors $[28,29,58]$. To investigate the determinants that contribute to reduced MPIs to MVC in treatment-naïve C-HIV infected subjects, we next analyzed V3 sequences of Envs that displayed plateaus below 100\% in 293-Affinofile $\mathrm{CD} 4^{\mathrm{med}} / \mathrm{CCR} 5^{\mathrm{hi}}$ cells, compared to their corresponding genetically-related Envs that were completely inhibited by MVC. For all subjects, the incompletely inhibited Envs displayed V3 sequences that differed from completely inhibited Envs recovered from the same subjects (Fig. 4). For the subsequent analyses we focussed on subjects 1375 and 1141, primarily because the incompletely inhibited Envs from these subjects displayed the lowest MPIs to MVC (Fig. 2) and had relatively consistent and/or discrete patterns of V3 changes whose functional properties could be more readily interrogated by mutagenesis studies (Fig. 4). Incompletely inhibited Envs from subject 1375 have a Gly residue at Env position 306, whereas completely inhibited Envs have Ser at this position. Similarly, completely inhibited Envs from subject 1441 possess Arg at position 305, whereas the majority of the incompletely inhibited Envs from subject 1441 have Gln at position 305. Although distinguishing amino acid changes also occurred at positions 320 and 328 for subject 1441, we focussed on the distinguishing change at position 305 because previous studies have shown that mutations at this position can contribute to CCR5 antagonist resistance by clinical HIV-1 subtype $C$ strains [51, 53]. To determine if these V3 loop mutations conferred incomplete MVC inhibition, we created residue swap mutants introducing Ser at position 306 for the incompletely inhibited Env 1375-E-2; Gly at position 306 for the completely inhibited 1375-E-21; Gln at position 305 for the completely inhibited Env 1441-E-7; and Arg at position 305 for the incompletely inhibited Env 1441-E-6 (Fig. 5). The mutant Envs retained an R5 phenotype when tested for infectivity on NP2-CD4/CCR5 and NP2-CD4/ CXCR4 cells (data not shown).

We next generated luciferase reporter viruses pseudotyped with the Env mutants, and performed MVC sensitivity assays in 293-Affinofile CD $4^{\text {med }} /$ CCR $5^{\text {hi }}$ cells (Fig. 6). Introduction of Gly306 into the completely inhibited 1375-E-21 Env led to a modest reduction in MPI from $98.3 \pm 1.9$ (mean $\% \pm$ standard deviation) to $92.2 \pm 0.5$; whilst introduction of Ser306 into the incompletely inhibited 1375-E-2 Env led to an increase in MPI from $36.1 \pm 2.9$ to $86.7 \pm 2.4$ and thus, partial restoration of MVC sensitivity. Similarly, introduction of Gln305 into the completely inhibited 1441-E-7 Env made no appreciable difference in MPI (101.3 \pm 1.6 to $99.9 \pm 0.6)$, and introduction of Arg305 into the incompletely inhibited 1441-E-6 Env completely restored MVC sensitivity $(67.4 \pm 4.0$ to $100.4 \pm 1.2)$. These results suggest that for the Envs tested, V3 loop mutations are necessary but not sufficient for baseline incomplete HIV-1 inhibition by $\mathrm{MVC}$, and that these mutations are strain specific.

Multiple studies have shown that the primary determinants of HIV-1 resistance to CCR 5 antagonists lie within the V3 loop of gp120 [28-30, 59-63]. In agreement with these studies, our results show that single V3 loop mutations are necessary for incomplete inhibition by MVC 

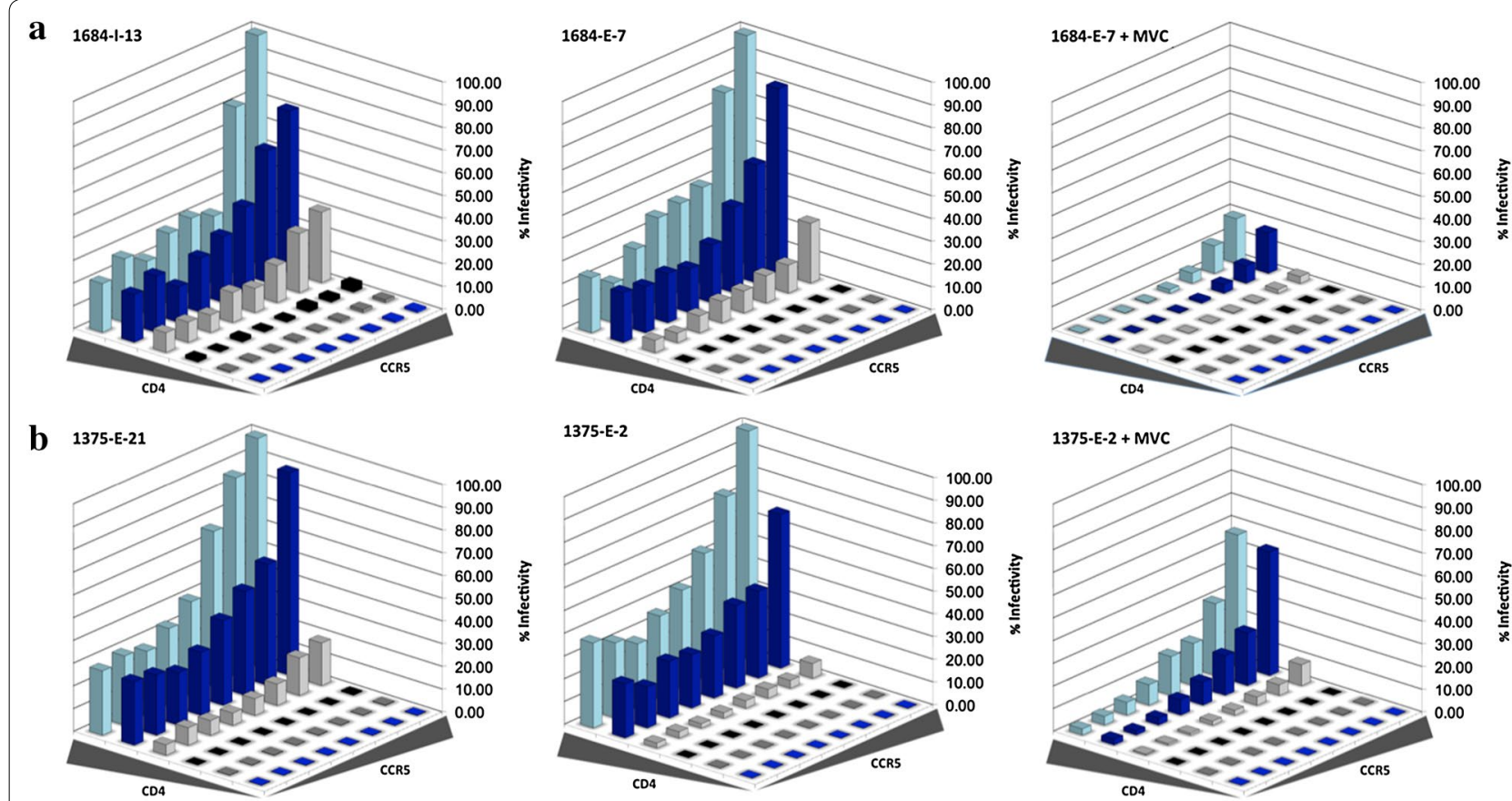

Fig. 3 The level of incomplete HIV-1 inhibition by MVC in subtype C Envs is dependent on the efficiency of interaction with MVC-bound CCR5. Luciferase reporter viruses from subjects 1684 (a) and 1375 (b) were used to infect 48 differentially-induced 293-Affinofile cell populations in the presence and absence of $10 \mu \mathrm{M}$ MVC as described in the "Methods". The percent infectivity was normalized that achieved in 293-Affinofile cells induced to express the maximal amount of CD4 and CCR5. The data shown are means of duplicate infections and are representative of three independent experiments

for the C-HIV Envs studied. However, the single V3 loop mutations were not sufficient to confer the incomplete inhibition phenotype suggesting that additional mutations outside of V3 may be required. This has been observed in other CCR5 antagonist resistant strains [29, 57, 58]. Furthermore, we showed that amino acid mutations important for incomplete MVC inhibition were strain specific, which is commonly observed amongst CCR5 antagonist resistant strains generated in vitro and in vivo $[28,29,57,58,64]$.

\section{Conclusions}

Our results demonstrate the presence of HIV-1 Env glycoproteins that display incomplete inhibition to the CCR5 antagonist MVC in a proportion of the ART-naïve subtype $\mathrm{C}$ infected individuals from our cohort. The incomplete inhibition profiles we describe are similar in mechanism to those seen in Envs isolated from individuals who fail MVC-containing therapy, which most likely involves the use of the MVC-modified form of CCR5 for entry. Furthermore, similar to genuine MVC-resistant strains, we were able to map residues critical for incomplete inhibition to the V3 loop of gp120. In agreement with our previous studies $[29,47]$ and those of other investigators [33, 34] on CCR5 antagonist resistance, we demonstrated that incomplete MVC inhibition profiles are more readily apparent in 293-Affinofile cells induced to express high levels of CCR5. Whether the C-HIV strains described here with incomplete MVC inhibition may act as scaffolds for the generation of genuine MVC resistance during MVC containing ART regimens is a possibility that remains to be determined by further studies.

\section{Additional files}

Additional file 1: Table S1. C-HIV Env clones used and their GenBank accession numbers.

Additional file 2: Table S2. Alternative coreceptor usage of Envs displaying incomplete HIV-1 inhibition by MVC compared to a representative Env from each subject that displays complete inhibition.

\section{Authors' contributions}

$K B, M R J, M R$ and PRG designed the experiments. KB, KC, JKF, PE and MR performed the experiments. $L O$ and $B L$ supplied critical reagents and helped interpret the results. MJC helped interpret the results. KB, MR and PRG wrote the manuscript. All authors helped edit the manuscript. All authors read and approved the final manuscript.

\section{Author details}

${ }^{1}$ Center for Biomedical Research, Burnet Institute, Melbourne, VIC, Australia. ${ }^{2}$ Department of Microbiology, La Trobe University, Melbourne, VIC, 


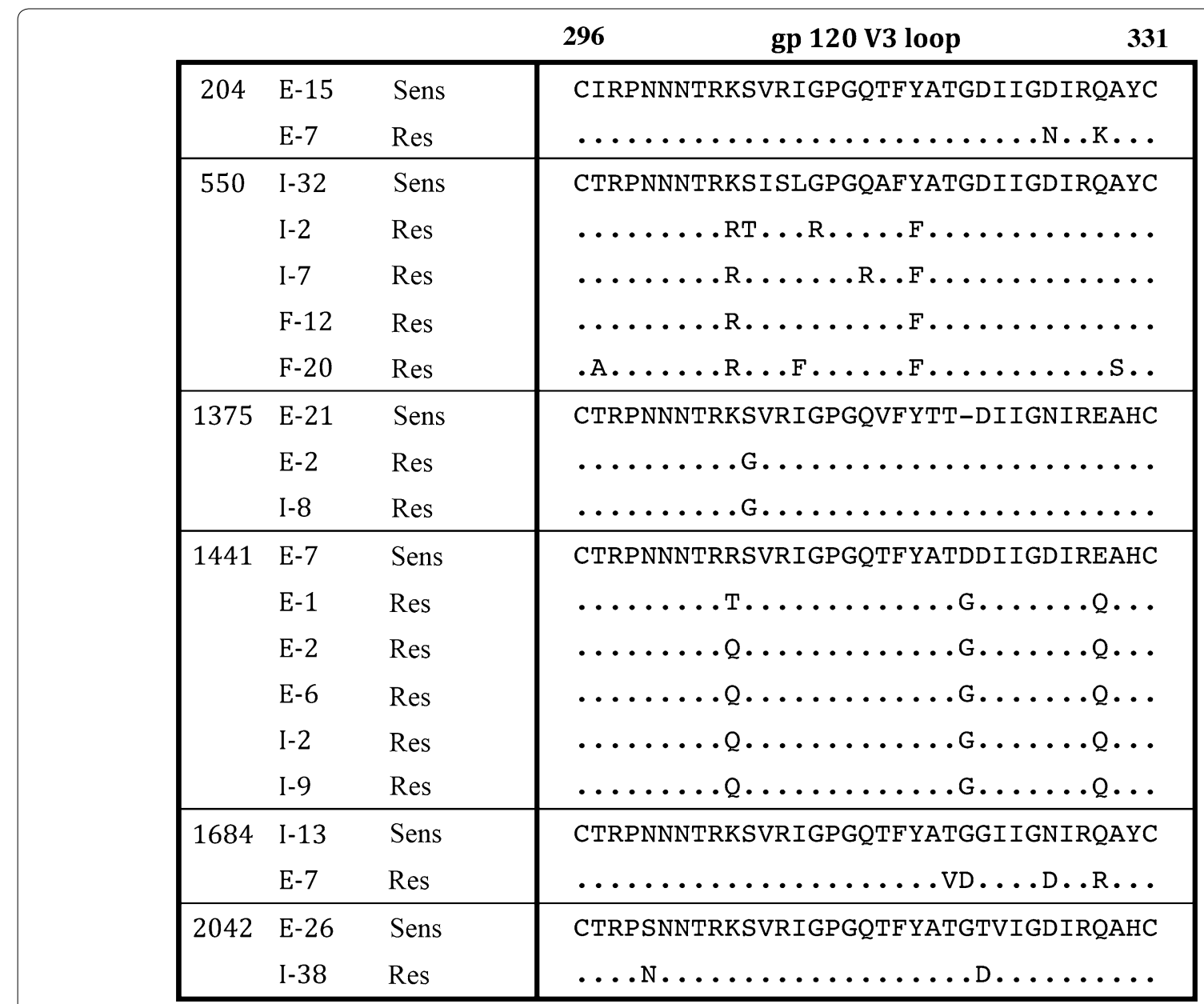

Fig. 4 V3 loop mutations distinguish Env clones from the same subjects that display complete or incomplete inhibition of HIV-1 by MVC. The V3 loop amino acid sequences of Env clones displaying incomplete inhibition by MVC and one representative Env clone displaying complete inhibition are shown from 6 subjects. Dots indicate residues identical to the representative sensitive clone and dashes indicate gaps. The numbering is based on the HXB2 Env amino acid sequence. Sens: Representative Env clone displaying complete inhibition by MVC, Res: Envs clones that display incomplete inhibition by MVC

\begin{tabular}{|c|c|c|}
\hline Subject & Env clone & V3 sequence \\
\hline 1375 & $\begin{array}{l}\text { E-2 } \\
\text { E-2 G306S } \\
\text { E-21 } \\
\text { E-21S306G }\end{array}$ & $\begin{array}{l}\text { CTRPNNNTRKGVRIGPGQVFYTT-DIIGNIREAHC } \\
\ldots \ldots \ldots \ldots \ldots \ldots \ldots \ldots \ldots \ldots \ldots \ldots \\
\text { CTRPNNNTRKSVRIGPGQVFYT-DIIGNIREAHC } \\
\ldots \ldots \ldots \ldots \ldots \ldots \ldots \ldots \ldots \ldots \ldots \ldots \ldots \ldots \ldots \ldots\end{array}$ \\
\hline 1441 & $\begin{array}{l}\text { E-6 } \\
\text { E-6 Q305R } \\
\text { E-7 } \\
\text { E-7 R3050 }\end{array}$ & 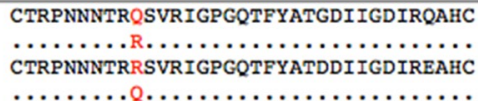 \\
\hline
\end{tabular}

Fig. 5 V3 loop amino acid sequence of Env mutants. The V3 loop sequences from the parental and mutant Env clones from two individuals are shown. The amino acid alterations are shown in red. Dots indicate residues identical to the parental strain and dashes indicate gaps. The numbering is based on the HXB2 Env amino acid sequence

Australia. ${ }^{3}$ Department of Biomedicine, Aarhus University, Aarhus, Denmark. ${ }^{4}$ School of Health and Biomedical Sciences, College of Science, Engineering and Health, RMIT University, Melbourne, VIC 3001, Australia. ${ }^{5}$ Department of Infectious Diseases, Monash University, Melbourne, VIC, Australia. ${ }^{6}$ Icahn School of Medicine at Mount Sinai, New York, NY, USA. ${ }^{7}$ Department of Medicine, Monash University, Melbourne, VIC, Australia. ${ }^{8}$ Department of Microbiology, Monash University, Melbourne, VIC, Australia. ${ }^{9}$ The Peter Doherty Institute for Infection and Immunity, University of Melbourne and Royal Melbourne Hospital, Melbourne, VIC 3000, Australia.

\section{Acknowledgements}

We thank J. Sodroski for providing the pSVIII-Env plasmid controls used in this study, as well as pCMV $\triangle \mathrm{P} 1 \triangle$ envpA and pHIV-1 Luc plasmids. We also thank D. Mosier and R. Nedellec for supplying the NP2-CD4/CCR5 cells, and N. Shimizu and $\mathrm{H}$. Hoshino for permission to use the NP2-CD4/CCR5 cells. Maraviroc was provided by Pfizer. This study was supported by a grant from the Australian National Health and Medical Research Council to PRG and MJC (APP1086178). KB is supported by a Victorian International Postgraduate Research Scholarship. JKF is supported by an RMIT Vice Chancellor's Postdoctoral Fellowship. KC and MR are supported by NHMRC Postdoctoral Training Fellowships. PRG was supported by an Australian Research Council (ARC) Future Fellowship. The authors gratefully acknowledge the contribution to this work of the Victorian Operational Infrastructure Support Program received by the Burnet Institute. 


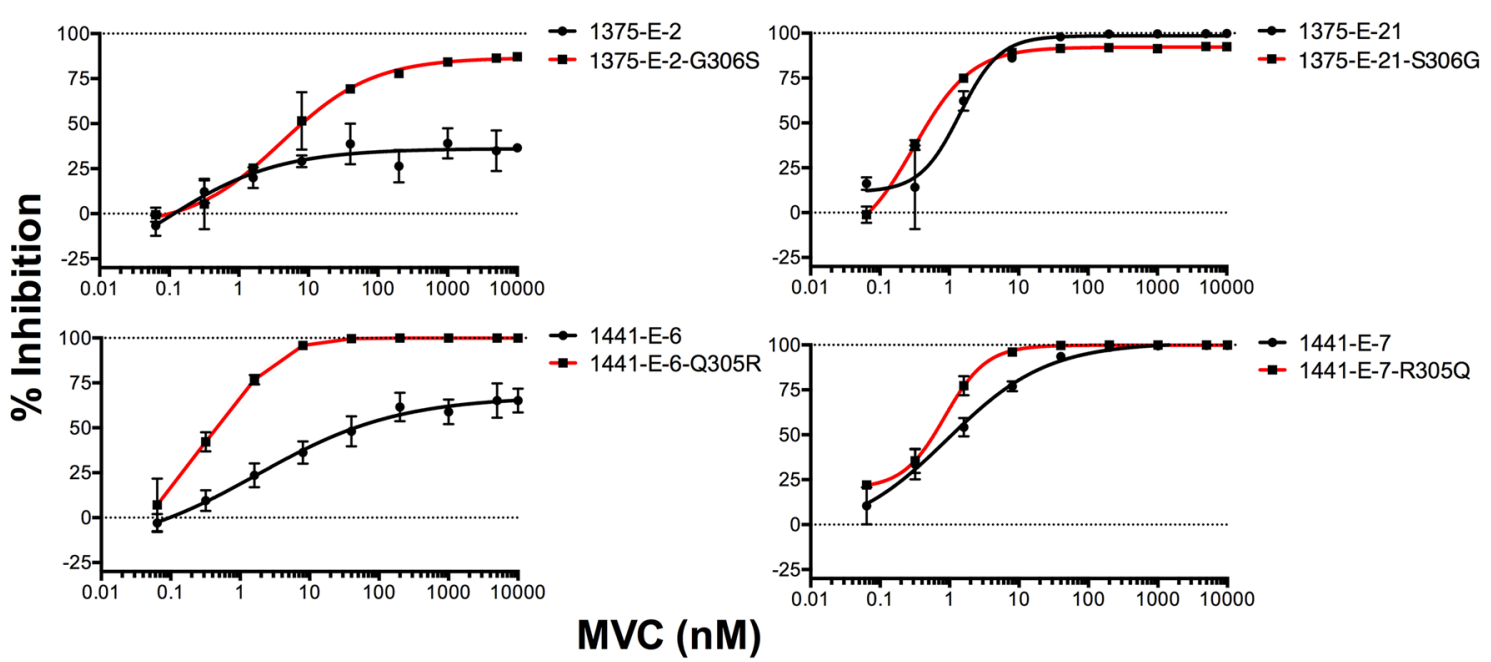

Fig. 6 V3 loop mutations are necessary but not sufficient for incomplete MVC inhibition phenotypes of HIV-1 subtype C Envs. Luciferase reporter viruses pseudotyped with parental and mutant Envs from subjects 1375 and 1441 were used to infect 293-Affinofile CD4 ${ }^{\text {med } / C C R 5 ~}{ }^{\text {hi }}$ cells in the presence of increasing concentrations of MVC. Virus inhibition curves were constructed as described in the "Methods". The data points represent the mean and standard error of triplicate wells from one representative experiment of three independent experiments

\section{Competing interests}

PRG was a past member of the ViiV Australia Scientific Advisory Board and has received honoraria. KC and PRG have received honoraria from ViiV for travel to conferences. The other authors declare that they have no competing interests.

Received: 26 April 2016 Accepted: 20 October 2016

Published online: 03 November 2016

\section{References}

1. Wilen CB, Tilton JC, Doms RW. HIV: cell binding and entry. Cold Spring Harb Perspect Med. 2012; 2(8). doi:10.1101/cshperspect.a006866

2. Dalgleish AG, Beverley PC, Clapham PR, Crawford DH, Greaves MF, Weiss RA. The CD4 (T4) antigen is an essential component of the receptor for the AIDS retrovirus. Nature. 1984;312(5996):763-7.

3. Maddon PJ, Dalgleish AG, McDougal JS, Clapham PR, Weiss RA, Axel R. The T4 gene encodes the AIDS virus receptor and is expressed in the immune system and the brain. Cell. 1986;47(3):333-48.

4. McDougal JS, Kennedy MS, Sligh JM, Cort SP, Mawle A, Nicholson JK. Binding of HTLV-III/LAV to T4+ T cells by a complex of the $110 \mathrm{~K}$ viral protein and the T4 molecule. Science. 1986;231(4736):382-5.

5. Alkhatib G, Combadiere C, Broder CC, Feng Y, Kennedy PE, Murphy PM, Berger EA. CC CKR5: a RANTES, MIP-1alpha, MIP-1 beta receptor as a fusion cofactor for macrophage-tropic HIV-1. Science. 1996;272(5270):1955-8.

6. Choe H, Farzan M, Sun Y, Sullivan N, Rollins B, Ponath PD, Wu L, Mackay CR, LaRosa G, Newman W, et al. The beta-chemokine receptors CCR3 and CCR5 facilitate infection by primary HIV-1 isolates. Cell. 1996;85(7):1135-48.

7. Deng H, Liu R, Ellmeier W, Choe S, Unutmaz D, Burkhart M, Di Marzio P, Marmon S, Sutton RE, Hill CM, et al. Identification of a major co-receptor for primary isolates of HIV-1. Nature. 1996;381 (6584):661-6.

8. Dragic T, Litwin V, Allaway GP, Martin SR, Huang Y, Nagashima KA, Cayanan C, Maddon PJ, Koup RA, Moore JP, et al. HIV-1 entry into CD4+ cells is mediated by the chemokine receptor CC-CKR-5. Nature. 1996:381 (6584):667-73.

9. Feng Y, Broder CC, Kennedy PE, Berger EA. HIV-1 entry cofactor: functional cDNA cloning of a seven-transmembrane, $G$ protein-coupled receptor. Science. 1996;272(5263):872-7.

10. Kwong PD, Wyatt R, Robinson J, Sweet RW, Sodroski J, Hendrickson WA. Structure of an HIV gp120 envelope glycoprotein in complex with the CD4 receptor and a neutralizing human antibody. Nature. 1998;393(6686):648-59.

11. Rizzuto CD, Wyatt R, Hernandez-Ramos N, Sun Y, Kwong PD, Hendrickson WA, Sodroski J. A conserved HIV gp120 glycoprotein structure involved in chemokine receptor binding. Science. 1998;280(5371):1949-53.

12. Wyatt R, Kwong PD, Desjardins E, Sweet RW, Robinson J, Hendrickson WA, Sodroski JG. The antigenic structure of the HIV gp120 envelope glycoprotein. Nature. 1998;393(6686):705-11.

13. Cormier EG, Persuh M, Thompson DA, Lin SW, Sakmar TP, Olson WC, Dragic T. Specific interaction of CCR5 amino-terminal domain peptides containing sulfotyrosines with HIV-1 envelope glycoprotein gp120. Proc Natl Acad Sci USA. 2000:97(11):5762-7.

14. Farzan M, Choe H, Vaca L, Martin K, Sun Y, Desjardins E, Ruffing N, Wu L, Wyatt R, Gerard N, et al. A tyrosine-rich region in the N terminus of CCR5 is important for human immunodeficiency virus type 1 entry and mediates an association between gp120 and CCR5. J Virol. 1998;72(2):1160-4.

15. Huang CC, Lam SN, Acharya P, Tang M, Xiang SH, Hussan SS, Stanfield RL, Robinson J, Sodroski J, Wilson IA, et al. Structures of the CCR5 N terminus and of a tyrosine-sulfated antibody with HIV-1 gp120 and CD4. Science. 2007;317(5846):1930-4.

16. Huang CC, Tang M, Zhang MY, Majeed S, Montabana E, Stanfield RL, Dimitrov DS, Korber B, Sodroski J, Wilson IA, et al. Structure of a V3-containing HIV-1 gp120 core. Science. 2005;310(5750):1025-8.

17. Cormier EG, Dragic T. The crown and stem of the $V 3$ loop play distinct roles in human immunodeficiency virus type 1 envelope glycoprotein interactions with the CCR5 coreceptor. J Virol. 2002;76(17):8953-7.

18. Cooper DA, Heera J, Goodrich J, Tawadrous M, Saag M, Dejesus E, Clumeck N, Walmsley S, Ting N, Coakley E, et al. Maraviroc versus efavirenz, both in combination with zidovudine-lamivudine, for the treatment of antiretroviral-naive subjects with CCR5-tropic HIV-1 infection. J Infect Dis. 2010;201(6):803-13.

19. Fatkenheuer G, Nelson M, Lazzarin A, Konourina I, Hoepelman Al, Lampiris H, Hirschel B, Tebas P, Raffi F, Trottier B, et al. Subgroup analyses of maraviroc in previously treated R5 HIV-1 infection. N Engl J Med. 2008;359(14):1442-55.

20. Gulick RM, Lalezari J, Goodrich J, Clumeck N, DeJesus E, Horban A, Nadler J, Clotet B, Karlsson A, Wohlfeiler M, et al. Maraviroc for previously treated patients with R5 HIV-1 infection. N Engl J Med. 2008;359(14):1429-41.

21. Fenyo EM, Fiore J, Karlsson A, Albert J, Scarlatti G. Biological phenotypes of HIV-1 in pathogenesis and transmission. Antibiot Chemother. 1971:1994(46):18-24. 
22. van't Wout AB, Kootstra NA, Mulder-Kampinga GA, Albrecht-van Lent N, Scherpbier HJ, Veenstra J, Boer K, Coutinho RA, Miedema F, Schuitemaker H. Macrophage-tropic variants initiate human immunodeficiency virus type 1 infection after sexual, parenteral, and vertical transmission. J Clin Invest. 1994;94(5):2060-7.

23. Zhu T, Mo H, Wang N, Nam DS, Cao Y, Koup RA, Ho DD. Genotypic and phenotypic characterization of HIV-1 patients with primary infection. Science. 1993;261(5125):1179-81.

24. Bai Q, Zhang Y, Li X, Chen W, Liu H, Yao X. Computational study on the interaction between CCR5 and HIV-1 entry inhibitor maraviroc: insight from accelerated molecular dynamics simulation and free energy calculation. Phys Chem Chem Phys. 2014;16(44):24332-8.

25. Dragic T, Trkola A, Thompson DA, Cormier EG, Kajumo FA, Maxwell E, Lin SW, Ying W, Smith SO, Sakmar TP, et al. A binding pocket for a small molecule inhibitor of HIV-1 entry within the transmembrane helices of CCR5. Proc Natl Acad Sci USA. 2000;97(10):5639-44

26. Tamamis P, Floudas CA. Molecular recognition of CCR5 by an HIV-1 gp120 V3 loop. PLoS ONE. 2014;9(4):e95767.

27. Tsamis F, Gavrilov S, Kajumo F, Seibert C, Kuhmann S, Ketas T, Trkola A, Palani A, Clader JW, Tagat JR, et al. Analysis of the mechanism by which the small-molecule CCR5 antagonists SCH-351125 and SCH350581 inhibit human immunodeficiency virus type 1 entry. J Virol. 2003;77(9):5201-8.

28. Westby M, Smith-Burchnell C, Mori J, Lewis M, Mosley M, Stockdale M, Dorr P, Ciaramella G, Perros M. Reduced maximal inhibition in phenotypic susceptibility assays indicates that viral strains resistant to the CCR5 antagonist maraviroc utilize inhibitor-bound receptor for entry. J Virol. 2007;81(5):2359-71

29. Roche M, Salimi H, Duncan R, Wilkinson BL, Chikere K, Moore MS, Webb $\mathrm{NE}$, Zappi H, Sterjovski J, Flynn JK, et al. A common mechanism of clinical HIV-1 resistance to the CCR5 antagonist maraviroc despite divergent resistance levels and lack of common gp120 resistance mutations. Retrovirology. 2013;10:43.

30. Tilton JC, Wilen CB, Didigu CA, Sinha R, Harrison JE, Agrawal-Gamse C, Henning EA, Bushman FD, Martin JN, Deeks SG, et al. A maravirocresistant HIV-1 with narrow cross-resistance to other CCR5 antagonists depends on both $\mathrm{N}$-terminal and extracellular loop domains of drugbound CCR5. J Virol. 2010;84(20):10863-76.

31. Sterjovski J, Roche M, Churchill MJ, Ellett A, Farrugia W, Gray LR, Cowley D, Poumbourios $\mathrm{P}$, Lee B, Wesselingh SL, et al. An altered and more efficient mechanism of CCR5 engagement contributes to macrophage tropism of CCR5-using HIV-1 envelopes. Virology. 2010;404(2):269-78.

32. Isaacman-Beck J, Hermann EA, Yi Y, Ratcliffe SJ, Mulenga J, Allen S, Hunter E, Derdeyn CA, Collman RG. Heterosexual transmission of human immunodeficiency virus type 1 subtype C: macrophage tropism, alternative coreceptor use, and the molecular anatomy of CCR5 utilization. J Virol. 2009;83(16):8208-20.

33. Ping LH, Joseph SB, Anderson JA, Abrahams MR, Salazar-Gonzalez JF, Kincer LP, Treurnicht FK, Arney L, Ojeda S, Zhang M, et al. Comparison of viral Env proteins from acute and chronic infections with subtype $C$ human immunodeficiency virus type 1 identifies differences in glycosylation and CCR5 utilization and suggests a new strategy for immunogen design. J Virol. 2013;87(13):7218-33.

34. Parker ZF, lyer SS, Wilen CB, Parrish NF, Chikere KC, Lee FH, Didigu CA, Berro R, Klasse PJ, Lee B, et al. Transmitted/founder and chronic HIV-1 envelope proteins are distinguished by differential utilization of CCR5. J Virol. 2013:87(5):2401-11.

35. Abraha A, Nankya IL, Gibson R, Demers K, Tebit DM, Johnston E, Katzenstein D, Siddiqui A, Herrera C, Fischetti L, et al. CCR5- and CXCR4-tropic subtype $C$ human immunodeficiency virus type 1 isolates have a lower level of pathogenic fitness than other dominant group M subtypes: implications for the epidemic. J Virol. 2009;83(11):5592-605.

36. Arien KK, Vanham G, Arts EJ. Is HIV-1 evolving to a less virulent form in humans? Nat Rev Microbiol. 2007;5(2):141-51.

37. Gorry PR, Ancuta P. Coreceptors and HIV-1 pathogenesis. Curr HIV/AIDS Rep. 2011:8:45-53.

38. Jakobsen MR, Cashin K, Roche M, Sterjovski J, Ellett A, Borm K, Flynn J, Erikstrup C, Gouillou M, Gray LR, et al. Longitudinal analysis of CCR5 and CXCR4 usage in a cohort of antiretroviral therapy-naive subjects with progressive HIV-1 subtype C infection. PLoS ONE. 2013;8(6):e65950.
39. Chikere K, Webb NE, Chou T, Borm K, Sterjovski J, Gorry PR, Lee B. Distinct HIV-1 entry phenotypes are associated with transmission, subtype specificity, and resistance to broadly neutralizing antibodies. Retrovirology. 2014;11:48. doi:10.1186/1742-4690-11-48.

40. Cashin K, Jakobsen MR, Sterjovski J, Roche M, Ellett A, Flynn JK, Borm K, Gouillou M, Churchill MJ, Gorry PR. Linkages between HIV-1 specificity for CCR5 or CXCR4 and in vitro usage of alternative coreceptors during progressive HIV-1 subtype C infection. Retrovirology. 2013;10:98.

41. Coetzer M, Nedellec R, Cilliers T, Meyers T, Morris L, Mosier DE. Extreme genetic divergence is required for coreceptor switching in HIV-1 subtype C. J Acquir Immune Defic Syndr. 2011;56:9-15.

42. Nedellec R, Coetzer M, Shimizu N, Hoshino H, Polonis VR, Morris L, Martensson UE, Binley J, Overbaugh J, Mosier DE. Virus entry via the alternative coreceptors CCR3 and FPRL1 differs by human immunodeficiency virus type 1 subtype. J Virol. 2009;83(17):8353-63.

43. Soda Y, Shimizu N, Jinno A, Liu HY, Kanbe K, Kitamura T, Hoshino H. Establishment of a new system for determination of coreceptor usages of HIV based on the human glioma NP-2 cell line. Biochem Biophys Res Commun. 1999;258(2):313-21.

44. Johnston SH, Lobritz MA, Nguyen S, Lassen K, Delair S, Posta F, Bryson YJ, Arts EJ, Chou T, Lee B. A quantitative affinity-profiling system that reveals distinct CD4/CCR5 usage patterns among human immunodeficiency virus type 1 and simian immunodeficiency virus strains. J Virol. 2009;83(21):11016-26.

45. Gray L, Roche M, Churchill MJ, Sterjovski J, Ellett A, Poumbourios P, Sherieff S, Wang B, Saksena N, Purcell DF, et al. Tissue-specific sequence alterations in the human immunodeficiency virus type 1 envelope favoring CCR5 usage contribute to persistence of dual-tropic virus in the brain. J Virol. 2009;83(11):5430-41.

46. Sterjovski J, Churchill MJ, Ellett A, Gray LR, Roche MJ, Dunfee RL, Purcell DF, Saksena N, Wang B, Sonza S, et al. Asn 362 in gp120 contributes to enhanced fusogenicity by CCR5-restricted HIV-1 envelope glycoprotein variants from patients with AIDS. Retrovirology. 2007:4:89.

47. Roche M, Jakobsen MR, Ellett A, Salimiseyedabad H, Jubb B, Westby M, Lee B, Lewin SR, Churchill MJ, Gorry PR. HIV-1 predisposed to acquiring resistance to maraviroc (MVC) and other CCR5 antagonists in vitro has an inherent, low-level ability to utilize MVC-bound CCR5 for entry. Retrovirology. 2011;8:89.

48. Roche M, Jakobsen MR, Sterjovski J, Ellett A, Posta F, Lee B, Jubb B, Westby M, Lewin SR, Ramsland PA, et al. HIV-1 escape from the CCR5 antagonist maraviroc associated with an altered and less efficient mechanism of gp120-CCR5 engagement that attenuates macrophage-tropism. J Virol. 2011;85:4330-42.

49. Salimi H, Roche M, Webb N, Gray LR, Chikere K, Sterjovski J, Ellett A, Wesselingh SL, Ramsland PA, Lee B, et al. Macrophage-tropic HIV-1 variants from brain demonstrate alterations in the way gp120 engages both CD4 and CCR5. J Leukoc Biol. 2013;93(1):113-26.

50. Chikere K, Chou T, Gorry PR, Lee B. Affinofile profiling: how efficiency of CD4/CCR5 usage impacts the biological and pathogenic phenotype of HIV. Virology. 2013:435(1):81-91.

51. Mori J, Mosley M, Lewis M, Simpson P, Toma J, Huang W, Whitcomb J, Ciaramella G, Westby M. Characterization of maraviroc resistance in patients failing treatment with CCR5-tropic virus in MOTIVATE 1 and MOTIVATE 2. Antivir Ther. 2007;12:S12.

52. Karlsson I, Antonsson L, Shi Y, Karlsson A, Albert J, Leitner T, Olde B, Owman C, Fenyo EM. HIV biological variability unveiled: frequent isolations and chimeric receptors reveal unprecedented variation of coreceptor use. AIDS. 2003;17(18):2561-9.

53. Karlsson I, Antonsson L, Shi Y, Oberg M, Karlsson A, Albert J, Olde B, Owman C, Jansson M, Fenyo EM. Coevolution of RANTES sensitivity and mode of CCR5 receptor use by human immunodeficiency virus type 1 of the R5 phenotype. J Virol. 2004;78(21):11807-15.

54. Karlsson U, Antonsson L, Repits J, Medstrand P, Owman C, Kidd-Ljunggren K, Hagberg L, Svennerholm B, Jansson M, Gisslen M, et al. Mode of coreceptor use by R5 HIV type 1 correlates with disease stage: a study of paired plasma and cerebrospinal fluid isolates. AIDS Res Hum Retroviruses. 2009;25(12):1297-305.

55. Karlsson U, Repits J, Antonsson L, Cederfjall E, Ljungberg B, Alenius M, Sabirsh A, Gisslen M, Esbjornsson J, Jansson M. Reduced baseline sensitivity to maraviroc inhibition among R5 HIV-1 isolates from 
individuals with severe immunodeficiency. J Acquir Immune Defic Syndr. 2016;71(3):e79-82.

56. Parker ZF, lyer SS, Wilen CB, Parrish NF, Chikere KC, Lee FH, Didigu CA, Berro R, Klasse PJ, Lee B, et al. Transmitted/founder and chronic HIV-1 envelope proteins are distinguished by differential utilization of CCR5. J Virol. 2013;87:2401-11.

57. Anastassopoulou CG, Ketas TJ, Klasse PJ, Moore JP. Resistance to CCR5 inhibitors caused by sequence changes in the fusion peptide of HIV-1 gp41. Proc Natl Acad Sci USA. 2009;106(13):5318-23.

58. McNicholas PM, Mann PA, Wojcik L, Phd PQ, Lee E, McCarthy M, Shen J, Black TA, Strizki JM. Mapping and characterization of vicriviroc resistance mutations from HIV-1 isolated from treatment-experienced subjects enrolled in a phase II study (VICTOR-E1). J Acquir Immune Defic Syndr. 2011;56(3):222-9.

59. Henrich TJ, Tsibris AM, Lewine NR, Konstantinidis I, Leopold KE, Sagar M, Kuritzkes DR. Evolution of CCR5 antagonist resistance in an HIV-1 subtype C clinical isolate. J Acquir Immune Defic Syndr. 2010;55(4):420-7.

60. Ogert RA, Wojcik L, Buontempo C, Ba L, Buontempo P, Ralston R, Strizki J, Howe JA. Mapping resistance to the CCR5 co-receptor antagonist vicriviroc using heterologous chimeric HIV-1 envelope genes reveals key determinants in the C2-V5 domain of gp120. Virology. 2008;373(2):387-99.

61. Tsibris AM, Sagar M, Gulick RM, Su Z, Hughes M, Greaves W, Subramanian M, Flexner C, Giguel F, Leopold KE, et al. In vivo emergence of vicriviroc resistance in a human immunodeficiency virus type 1 subtype $\mathrm{C}$-infected subject. J Virol. 2008;82(16):8210-4.

62. Ogert RA, Hou Y, Ba L, Wojcik L, Qiu P, Murgolo N, Duca J, Dunkle LM, Ralston R, Howe JA. Clinical resistance to vicriviroc through adaptive V3 loop mutations in HIV-1 subtype D gp120 that alter interactions with the N-terminus and ECL2 of CCR5. Virology. 2010;400(1):145-55.

63. Pfaff JM, Wilen CB, Harrison JE, Demarest JF, Lee B, Doms RW, Tilton JC. HIV-1 resistance to CCR5 antagonists associated with highly efficient use of CCR5 and altered tropism on primary CD4+ T cells. J Virol. 2010;84(13):6505-14.

64. McNicholas P, Wei Y, Whitcomb J, Greaves W, Black TA, Tremblay CL, Strizki JM. Characterization of emergent HIV resistance in treatmentnaive subjects enrolled in a vicriviroc phase 2 trial. J Infect Dis. 2010;201(10):1470-80.

\section{Submit your next manuscript to BioMed Central and we will help you at every step:}

- We accept pre-submission inquiries

- Our selector tool helps you to find the most relevant journal

- We provide round the clock customer support

- Convenient online submission

- Thorough peer review

- Inclusion in PubMed and all major indexing services

- Maximum visibility for your research

Submit your manuscript at www.biomedcentral.com/submit 